\title{
壽䅫古淮 河道
}

徐近之

1950年夏季中國科學院成立了地理研究所䇾 龦虙, 决定把研究淍查的重點區域放在黄河同淮 河中下游, 並先從事黄河下游泛濫澡的調查。由於 中央人民政府把治淮列结國家桠济建設的重點，

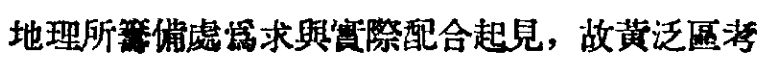
察除於9月下旬出墢,前往泛區。調查除出發不久
在淮河中游壽縣八公山南面找着了地質歷史上的 古淮河道, 若干同行對它發生興趣, 這淁特地简略 報运:嚴格說, 黄河下游和淮河是分不開的, 淮河 中下游受到黄河泛濫的災害最大; 我們調查是從 淮河中游到上游, 目的在朋睹黄泛沉䅡與冲别的 情形和影響。大家公認的黄河遙徙,在原史上已有

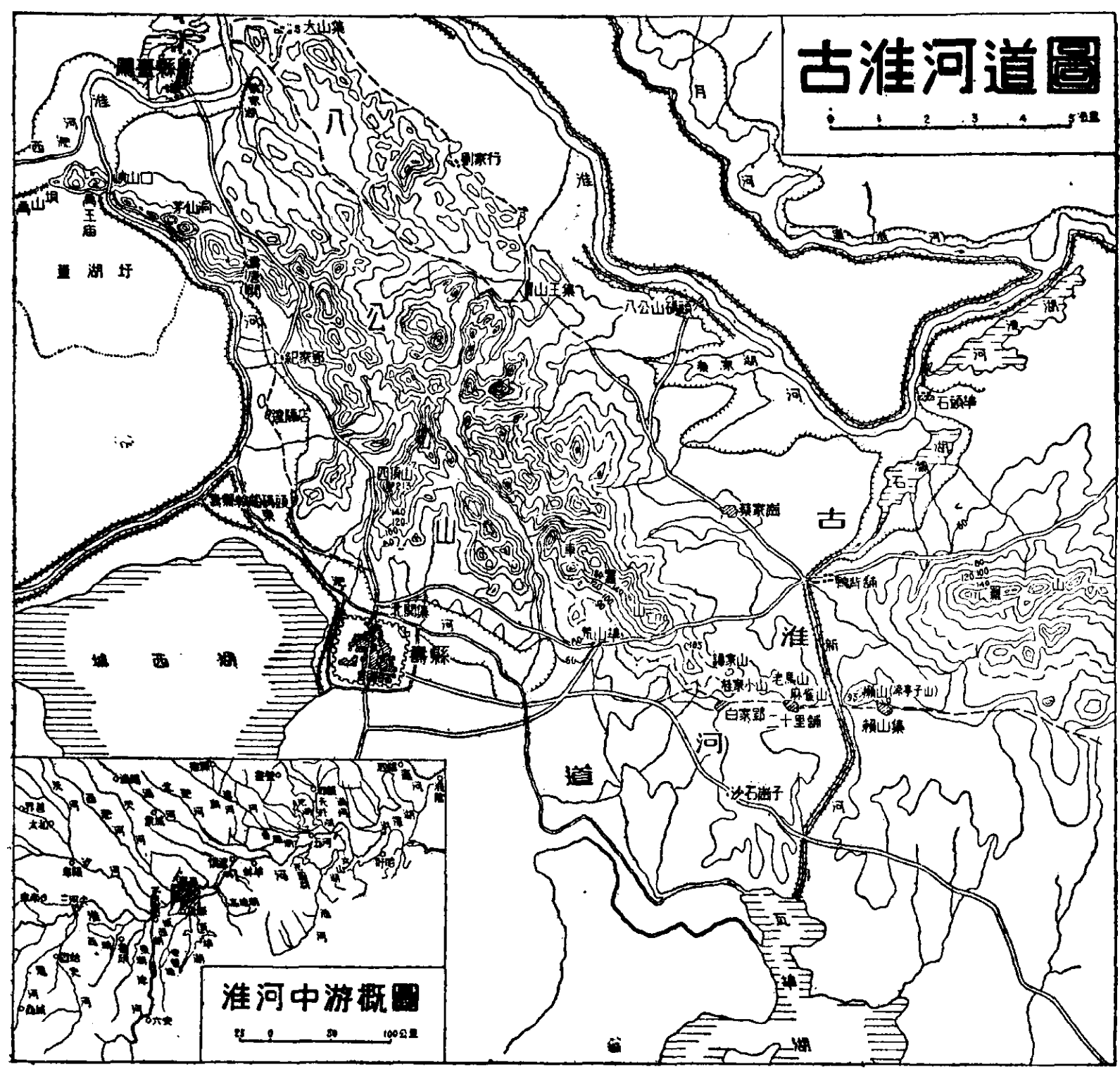


次次。這回調查的黄河泛濫區是 1938-1947 的泛

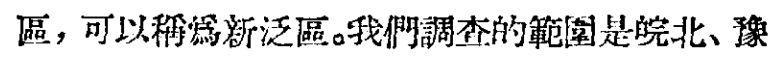
東、箱(沙)河與渦河战䦐的地帶。古淮河道的地位 是在這狹辰地帶的最東南面。

淮河中游大約是指洪澤湖以西到三河尖的一

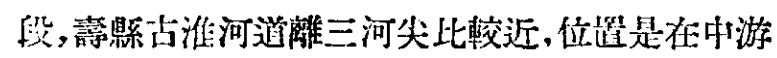

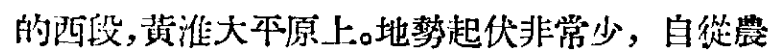

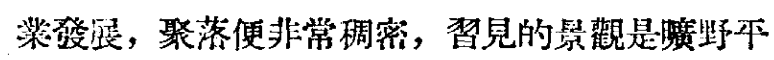
栁。

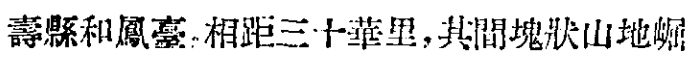

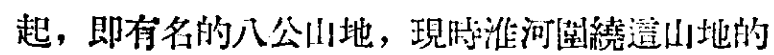
西、北、東三面成几字形的水道，几字的底部，便是 八公山地的南麓, 東西淮陮不過二十幾荘里。八公

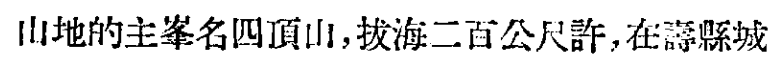
的䜣北面，從它的絕頂可以俯瞰整倜源交接地

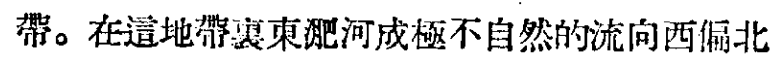
的方向,到善縣西北六、七里地方注入淮河。扎淖 湖的北部隐䄪可見, 從 20 里觔南流入湖的小水水

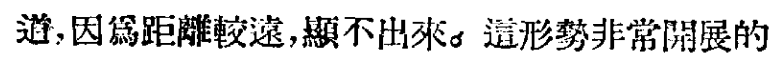
山原交接地带, 侹是占淮河道,它的西部是現時的 城西湖, 它的大部是東犱河, 它的東部是比較高起 的地區,嚴格裞是 20 里铺和賴山集中間的缺口; 把 筙淘撗大起來, 這比較高起的地區是車羅山和羅
山中間四、五個缺口南北的地方，除丘陵外，地面 起伏很小。這電缺口，地形學上叫做風口（wind gap), 現時新河所經的一個缺口, 比較最筧, 而且 海拔最低，據估計有 40 觡公尺。壽縣縣城的高度大 的是25公尺。

本文係一般性報導，對於占河道成因和歴史， 不疑多所諭及，所附地形圖是根提前參謀部测量 局应英分之一圖和日本佔領時期航空测量比例尺 祭大的圖拼繪而成。此區更可靠的大比例尺圖邆 沼有。

像八公山這樣的占老山體, 在淮河中游翰流

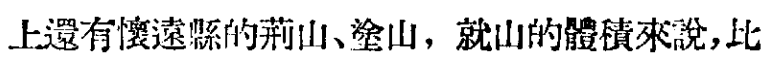
八公江要小得多, 所以單從地形上桃比較网處山

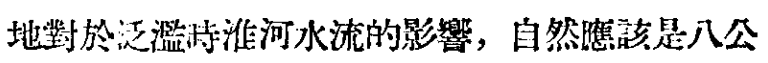
山山地要大些。從地圖上看起來,八公山以酉淮河 兩岸的湖泊又多又大，八公山以東踓则地在兩處 山地之間，淮河兩岸湖泊反小，而且少得多。襄有，

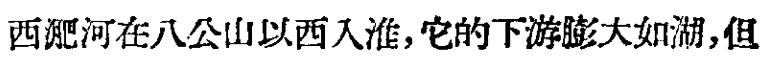
是現在的河口一段祇筧16公尺，造種特别而及反 常的現象，䫏然主要是由於八公山的攔阻蓄水影 響。同樣,在懷遠荊塗二川以上，苂河下游河道也

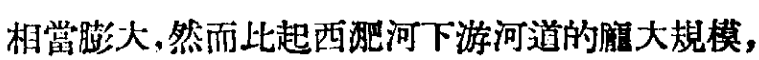
就小得多了，因筬篇幅的關係，附圖的範圈和比例

\section{古淮河道沿綫地質圖}

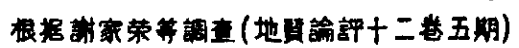

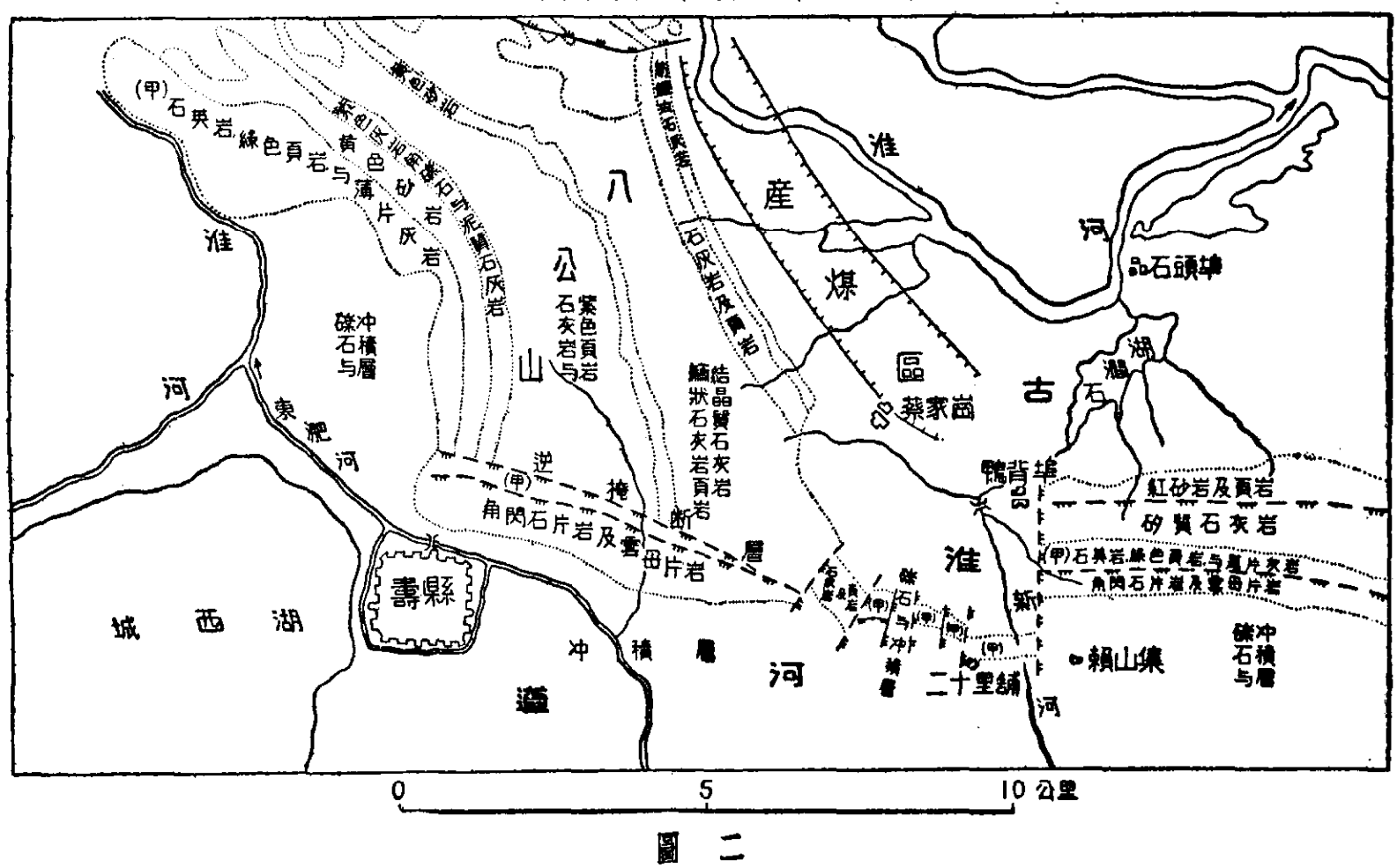




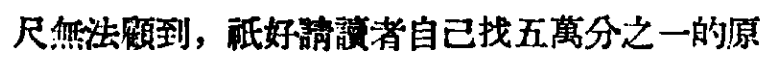
圖寥看。

淮河中游經過的的地既然不祇一處, 占老水 道也很可能不祇一處。我們所找到的善拲占淮河 道最明確部份, 是界於舜株山西段的羅山和人公 山東蒲部的車睢山中間,摆家山、桂家小山、老馬

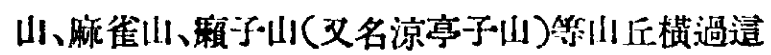
段占河道。在地質構造上造縄個具有連姀性的山 丘非常重要, 謝策榮先生把舜耕山和八公山合稱

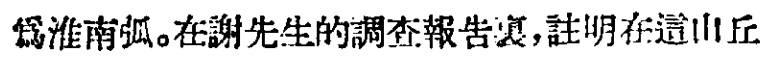

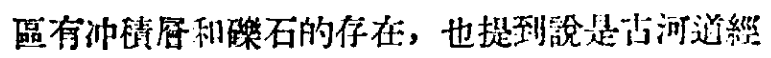
過，但是不留指朋是古淮河河道。至於占淮河道的

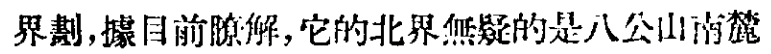
被截割破碎不壦的階地所在。至於南界则因地勢

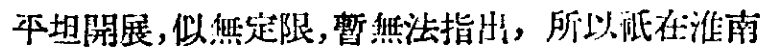
弧的連薮山丘區兩穷社明占淮河道字樣。

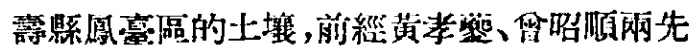
生調查, 從他們的土墥圆可以知道古淮河道沿能

\section{古淮河逼沿䋐土境

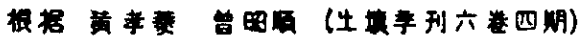

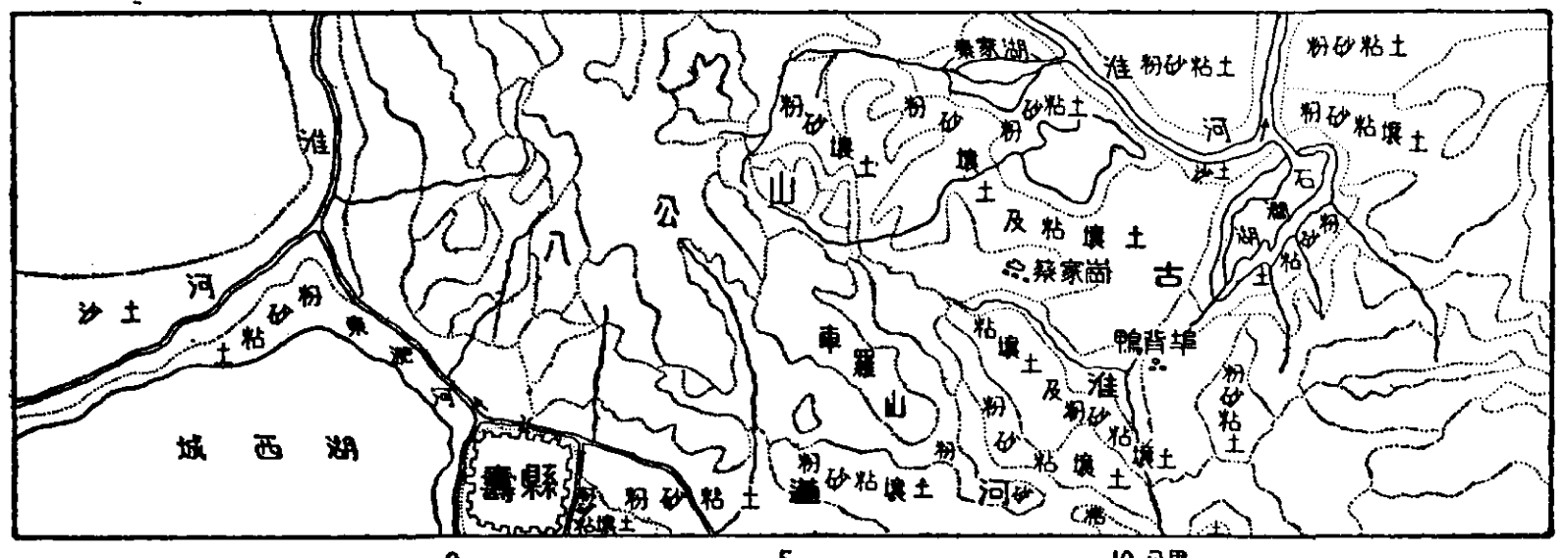

5

10 公里

圆

土壤情形。本交特附謝、黄、會幾位先生的地質和 土塆圆閶於占淮河道部份，以借作筬開運河計劃 的参榙。

我們兩次(1950年10月,1951年1月)在占淮河 道區調查, 認第它的存在是很自然的, 因第按地質 地形上的事貨, 所有湖泊都是短命的, 那然壽影古 淮河道不會是正埠湖出水道所造成, 也許是淮南 弧成立以前就是淮河所流䊗的。淮南弧和淮河的 弡育史並不簡單, 目前所知道的過於有限, 不過淮 南弧的造成是逽在第三紀以前, 想來這段占淮河 道的你在也早逑差得不會太多吧。

沿占淮河道我們所親見的地形上證㨜，有: (一)八公山南麓階地，已被械割成破碎小庍，這階 地裹面的片岩:被侵刢成功平頂石哇(Rock terrace)或石台(Rock platform),還樣的地形當非小河 流短㭙間所能造成。(二)壽䟢城到20里舖的公路,

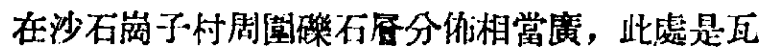
绵湖湖畔, 碟石多小而光滑, 其中有的磁石的岩

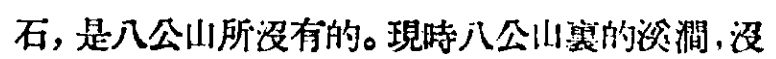

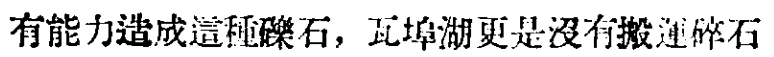
的能力。(三)占淮河道大部相當於現在的果狍河,

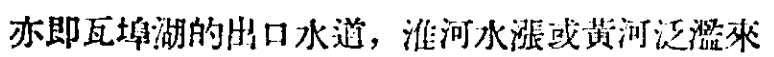
到時, 洪水經的東泡河灌進正坮湖, 水退挠, 全區 被普遍淤塞, 目前的東汁测正在大加䟽糛，使瓦绵 湖和城西湖成瓷淮河中游的蓄洪水庫。(四)瓦绵

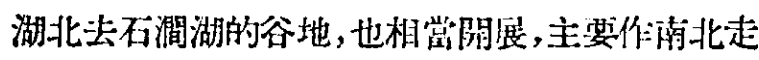

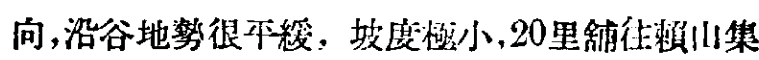

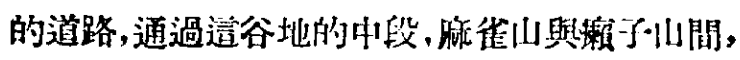
這谷地的筧度是 250 公尺餘。在这谷地泣，小水向 南北分流,1913-1917北洋軍閾洔代，㑆解冲監修 的新河河道便利用這南北開展的谷地。新河作均 筧30公尺,深8.9公尺，因给碰着堅硬的岩石，不能

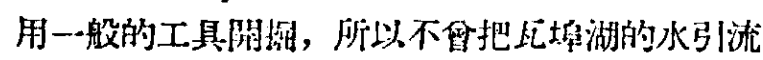

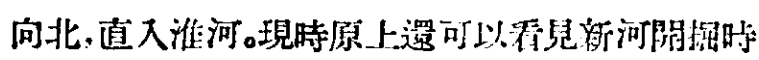

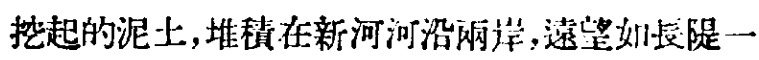

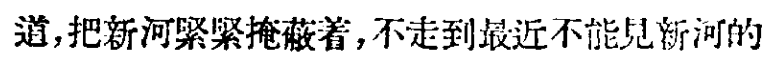


細流。(Zi)新河谷地以西的幾㑑山丘間的䊽口, 都

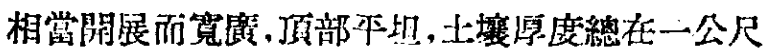

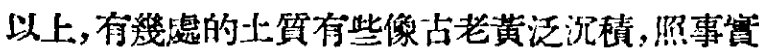

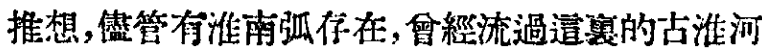
道是够兒展的。

在我們沼有地地考察以前，已經䑁得繞行八 公山儿字形的谁河水道太不自然; 從讀圖便斷定 八公山南應嗤占淮河道所楥。考察以後,從地樊地

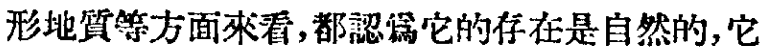

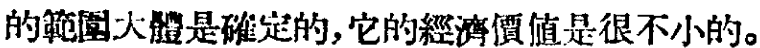
如果能沿這占河道開一焂運河，不但可以縮短航 程公七十龩里，同時更可以減輕八公山以西淮河 中游的水災; 尤其是言䅫縣城,自來是水城一座,
1933年泛温時, 人坐城睦上可以用洪水洗足, 蓄

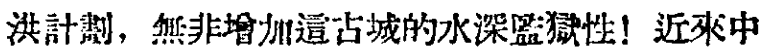

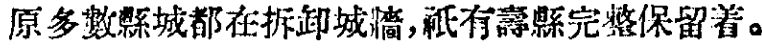

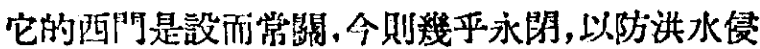

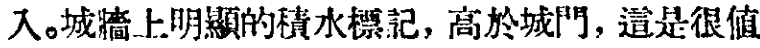

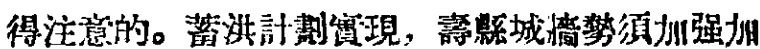

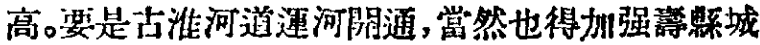
的隄岸，但是占城可以早些繁柴起来。给安赏起 見，造運河的開通最好等淮河恢復了它的道接入 海水道以媵，以免中游水啺流而下，一下游難洩成 桨。

我門對於壽縣古淮河道奇興無限的希案。

\section{上海市科技工作者弦表宣言擁護鎮壓反革命}

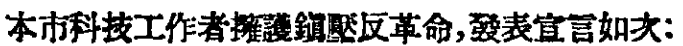

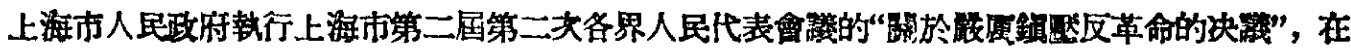

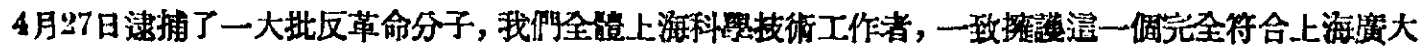
人民的需大利照與泊切要求的必要措施!

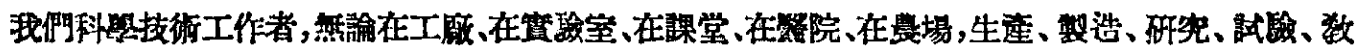

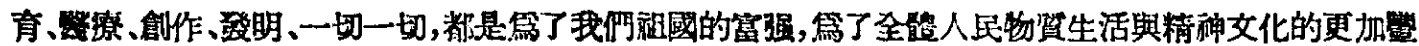

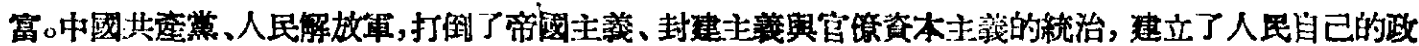

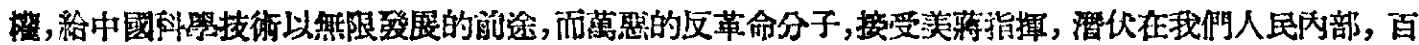

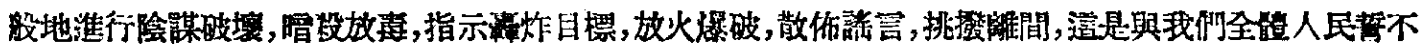

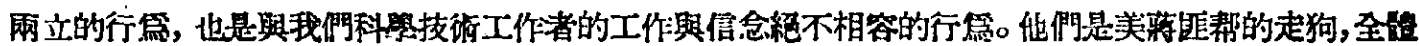

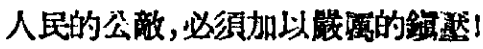

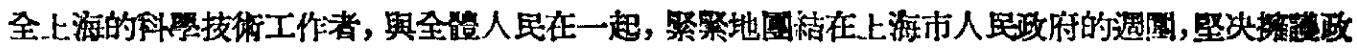

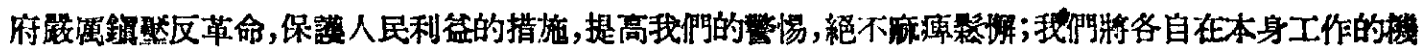

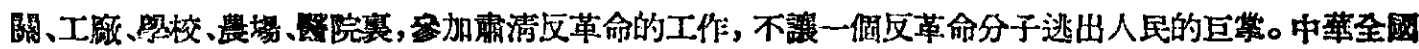

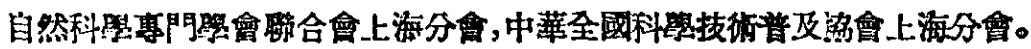

(女露派5月1日) 